\title{
Nostromo: un puente entre la novela y la historia
}

\author{
José Juan DÁvILA SoTA \\ Universidad Nacional Autónoma de México
}

En 1904, cuando apareció, Nostromo recibió casi de inmediato una cálida acogida tanto del público como de la crítica y despertó una gran curiosidad acerca del alcance del conocimiento de su autor sobre el continente americano y en especial sobre Latinoamérica. El poder evocativo de la novela y su capacidad de recrear personajes y ambientes exóticos pero concretos aumentaron la curiosidad del público lector. El autor, Joseph Conrad, ya había establecido una reputación como novelista cuyas obras se desarrollaban en lugares remotos y rodeados de una cierta aura de aventura, como el archipiélago malayo o el Congo. Se sabía que sus viajes de marino lo habían llevado a esos lugares, pero se ignoraba la extensión de sus conocimientos sobre América. Ahora ya se sabe que Conrad conoció este hemisferio de manera bastante superficial, no permaneció un tiempo largo en América y su conocimiento lo adquirió de pasada, por cuatro viajes que hizo a la Guadaloupe, Haití, Martinica, las islas de Saint Thomas y Nueva Orleans.

Joseph Conrad, novelista inglés por elección y polaco por origen, nació en 1857. Después de su lengua materna aprendió el francés, que por un tiempo pensó utilizar para escribir, pero optó por el inglés, aunque éste sólo lo empezó a aprender después de los veinte años, cuando se unió a la marina mercante de la Gran Bretaña. Almayer's Folly, su primera novela, se publicó en 1895 y desde ese momento continuó escribiendo hasta su muerte en 1924. Nostromo apareció en 1904 y casi unánimemente se reconoce como la obra maestra de Conrad. Con ella logró el deseo oculto de todo novelista que se respete: inventar un país completo, con sus gentes, olores, colores, accidentes geográficos, historia, gobierno, instituciones, revoluciones, golpes de estado, economía y problemas de modernización. De más está decir que no se trata de un país existente, real, al que el novelista disfraza con el nombre de Costaguana, sino de un vasto territorio imaginario en el que la novela se desarrolla. Conrad inventó este país en toda su integridad a partir de los viajes que ya mencioné, de la lectura de unos cuantos libros y, sobre todo, de su estadía imaginativa 
- lo dice él mismo en el prólogo a la novela - en las costas, montañas, valles, ciudades y aldeas de Costaguana.

Lo interesante es que el resultado de esa estadía creativa e imaginativa es verosímil, tiene un extraño aire de realidad, una concreción que rara vez se logra en novelas cuya acción se sitúa en países ajenos a la experiencia real del escritor. Pero más allá de esa concreción, lo que llama la atención del lector de hoy es que Nostromo parece tratar asuntos y problemas de actualidad. Después de más de noventa años de su publicación, parece como si la novela acabara de ser escrita. En realidad arroja más luz sobre los problemas sociopolíticos de muchos paises latinoamericanos que algunas obras no novelescas que han sido escritas precisamente para analizar datos tomados de la realidad y esclarecerla.

Sin profundizar, por el momento, demasiado en la visión pesimista y sombría de esta novela, se puede afirmar que en ella no están ausentes ni la simpatía ni la crítica, y que el esfuerzo de imaginación de Conrad está encaminado a entender el universo de los otros, para concluir que, en el fondo, los problemas del hombre son los mismos con independencia del lugar y del tiempo en que se presenten. Para Conrad no fue fácil llegar a esta conclusión, ya que antes debió apoderarse de un código ajeno, para después poderlo presentar a sus lectores (europeos cultos, principalmente ingleses de 1904), en términos tales que lo pudieran, fácilmente, captar y entender. Esta necesidad determina que los principales personajes de la novela sean europeos o se hayan europeizado por su educación y crianza. El matrimonio Gould, el capitán Mitchel y el doctor Monygham son ingleses; Martín Decoud, aunque nacido en Costaguana, creció y se educó en Francia, y el mismo Nostromo y Giorgio Viola son italianos.

Antes de continuar es útil hacer un breve resumen de la trama de la novela. Sulaco es la principal ciudad de la Provincia Occidental de la República de Costaguana y está enteramente dominada por la concesión Gould, que explota una gran mina de plata, financiada, en parte, por el capitalista estadounidense Holroyd. Gould es un idealista que piensa que los intereses materiales personificados en su mina tendrán el poder de traer la civilización y el progreso a la atrasada República. En realidad, la plata de la mina es una influencia corruptora que pasa de las esferas personales y morales a las de la política y la sociedad. Su influencia hace que Gould se aleje de su esposa, quien finalmente llega a ponerse de acuerdo con el doctor Monygham en que no hay paz en los intereses materiales. La mina financia al gobierno y es causa de una revolución o levantamiento. Durante él, Martín Decoud, dandy parisino por adopción y temperamento y periodista escéptico por necesidad, se enamora de la bella patriota Antonia Avellanos y da a luz la idea de la creación de una República Occidental separada de Costaguana. 
En un momento crucial de la revolución, Nostromo, el capataz de cargadores y líder del pueblo (quien es capaz de casi cualquier cosa por amor a la fama y al prestigio), recibe la importantísima encomienda de evitar que una gran cantidad de plata que ha sido extraída de la mina caiga en manos del enemigo. Por eso, en compañía de Martín Decoud, la transporta a bordo de una chalupa a una isla desierta en el Golfo Plácido. Sin embargo, durante la travesía, en plena noche, la chalupa choca con un barco que transporta tropas revolucionarias; todo el mundo piensa que la plata se ha hundido irremisiblemente, pero en realidad, Decoud y Nostromo logran llegar con el tesoro a una isla donde lo ocultan. Nostromo deja a Martín en la isla y nada a tierra firme con la intención de informar a sus propietarios acerca del destino de la plata. Mientras tanto, Decoud, enfrentado a su soledad y escepticismo, se suicida; Nostromo, antes de poder dar su informe, se entera de la muerte de su compañero y se da cuenta que puede apoderarse del tesoro sin ningún temor, puesto que todos lo dan por perdido en las profundidades del golfo. Finalmente, la facción separatista triunfa y Nostromo, resentido con una sociedad que lo usa pero no lo recompensa, calla el destino de la plata y adquiere una pequeña embarcación con la que en sucesivos viajes a la isla se hace rico poco a poco. Hasta aquí el plan de Nostromo parece perfecto, sin embargo, al poco tiempo en la isla se construye un faro que es puesto bajo el cuidado de Giorgio Viola y de sus dos hijas, quienes son los dos amores de Nostromo. Una noche, cuando éste va a buscar su plata. Viola lo confunde con un pretendiente de Gisele, a quien odia y desprecia, y le dispara causándole la muerte.

El resumen precedente no le hace justicia a la novela, pero lo que verdaderamente importa es saber si la imagen del país latinoamericano que presenta puede ser aceptada por un lector de nuestro tiempo y nuestros paises. En principio, dada su profundidad artística, la novela trasciende fácilmente las limitaciones de su tiempo y espacio y se vuelve un puente que sirve para unir la visión de los otros con el concepto que tenemos de nosotros mismos. Por otro lado, en sus páginas se presenta una problemática que aún sigue vigente. Para explorar el porqué de su validez actual se puede partir de un concepto de novela como narración extensa en prosa que contiene personajes, acciones, incidentes y trama, y en la que predominan los elementos ficticios, es decir, falsos o inventados. Nostromo, sin embargo, se presenta al lector como novela realista, y como tal, más emparentada con la novelística de los siglos XVIII y XIX que con la del XX. En el siglo XVIII era común que se reclamara para las novelas el estatus de historia verdadera (cosa que no hace Nostromo); los lectores, por su parte, aunque no creyeran en la veracidad de la novela, jugaban a aceptar su carácter de verdad aunque sólo fuera mientras durara su lectura. 
En el siglo XIX la novela europea buscó en muchos casos (principalmente hacia el final del siglo) ser un espejo que reflejara la realidad, sin distorsiones, tal como lo expresó memorablemente Stendhal en su famosa metáfora. En ella, la novela se compara a un espejo que se pasea a lo largo de un camino reflejando a veces el cielo y a veces el lodo; es decir, la novela muestra una imagen tanto de los aspectos más elevados como de los más sórdidos de la vida. El novelista que decide trabajar dentro de esta convención tiene que presentar sus creaciones con una fuerza tal que sea suficiente para convencer al lector, y para lograrlo incluye "todos" los vicios, pasiones, riquezas y miserias de la realidad. En esto se parece al historiador a quien no le está permitido idealizar los datos que obtiene del mundo real.

Nostromo, sin lugar a dudas, deja en el lector la impresión profunda de que su material podría haber sido tomado de la realidad. Una vez que el lector supera las primeras cuarenta o cincuenta páginas y olvida algunas olvidables del último tercio de la novela, queda en él la impresión de que Costaguana y sus habitantes podrian tener una existencia en el mundo exterior a la novela y que esa existencia es independiente del lector. La sensación del lector es que el narrador conoce completamente el mundo de la novela, de que sabe mucho más de lo que cuenta y de que ha escogido lo más significativo entre lo mucho que sabe. El lector intuye que sería imposible contar todo lo que el narrador sabe de Costaguana y que por eso solamente le presenta un vistazo, una serie de pequeñas viñetas de personajes y de incidentes que parecen menores pero que, infaliblemente, hacen que el territorio se llene de seres y acciones vivos y reales.

Quizá de esto proviene la sensación de que al leer la novela se penetra en una obra histórica, de que uno comparte con el narrador incidentes y acciones realmente sucedidos. No en balde la crítica usa con frecuencia la palabra historia para referirse a Nostromo. Si comparamos nuestra idea de novela con la definición de historia que da Hayden White en su obra Metahistoria, veremos que entre ambas existe una sensible aproximación. White afirma que una obra histórica en su aspecto más manifiesto es "una estructura verbal en forma de discurso en prosa narrativa que dice ser un modelo, o imagen, de estructuras y procesos pasados con el fin de explicar lo que fueron representándolos". ${ }^{1}$

En esta concepción de la obra histórica destaca tanto su carácter explicativo, expresamente subrayado por el autor, como su carácter mimético o explicativo ("modelo o imagen"). White también pone énfasis en que son los hechos del pasado los que se explican. La novela, por su parte, no se limita a

\footnotetext{
' Véase Hayden WHITE, Metahistoria; la imaginación histórica en la Europa del siglo $X I X$. México, FCE, 1992.
} 
explicar, sino que representa por medio del lenguaje no hechos que pertenecen al pasado como la historia, sino hechos que pertenecen a la conciencia del escritor, quien, a su vez, los ha elaborado partiendo de la realidad y los ha plasmado dentro de una forma arquetípica. Cuando el escritor hace uso de esta forma, al representar esos hechos también los explica, ya que los coloca dentro de un marco en el que la voz narrativa no da igual importancia a todos los hechos; por el contrario, a veces subraya o parece omitir, a veces, ironiza o juzga. Por eso, el lector avisado sabe que los hechos que presentan las novelas no pertenecen a la realidad, no son históricos, pero sí tienen que ver con la realidad, puesto que en ella encuentran su sustento último; la realidad les dio origen y el escritor sólo los ha mediado para presentarlos al lector.

Por otro lado, la novela no tiene primordialmente el carácter explicativo que le atribuye White a la historia, y, sin embargo, en aparente paradoja, puede enriquecer nuestra vida al ponernos en contacto con experiencias ajenas; además; puesto que no ofrece abiertamente una explicación de las experiencias imaginativas que presenta, demanda del lector un esfuerzo de imaginación que lo lleve a obtener una interpretación. Este esfuerzo hace que el lector se convierta, como el historiador, en un intérprete de la realidad y que aporte para interpretarla sus propias experiencias y conocimientos.

En la historia las posiciones teóricas y metodológicas del historiador determinan sus posibilidades de explicación y, por tanto, la explicación puede existir en un plano separado del plano del relato. En la novela, en cambio, el relato mismo es la explicación; la trama, es decir, la estructura de lo narrado, debe formar un todo orgánico tan complejo como la realidad misma. La forma arquetípica del relato y la distancia que se establece entre el autor, el narrador (o los narradores), lo narrado y el lector proporcionan a la novela toda una gama de posibilidades explicativas. Por supuesto que las explicaciones son de orden diferente; la histórica apela primordialmente al intelecto; la artística, sin dejar de lado lo intelectual, se dirige a las emociones y sentimientos. Si en la historia la posición desde la que se juzga depende de la postura ideológica y metodológica del autor, en las buenas novelas esto no siempre es verdad.

En Nostromo, por ejemplo, vemos que no existe un punto de vista único desde el que se pueda juzgar sino que el juicio se puede hacer desde varios puntos de vista y con distintos énfasis. En Nostromo no existe una posibilidad única de establecer autoridad; más bien, lo que existe en ésta, como en muchas otras novelas, son múltiples puntos de vista y múltiples posiciones de autoridad que se presentan al lector para que escoja desde cuál quiere juzgar los acontecimientos. Pero el lector, al escoger una posibilidad, no elimina las otras, que siguen existiendo y que pueden retomarse en cualquier momento. Por otro lado, es cierto que Nostromo tiene una fuerte tendencia a la ambigüedad y a la 
oscuridad y, sin embargo, guía al lector en su búsqueda de la verdad de los hechos, esto se debe a que, por supuesto, esta "verdad" no pertenece al tipo de verdades cientificas o factuales en que los hechos existen con independencia de su interpretación ( $y$, muchas veces, existen precisamente para ser interpretados), sino a aquellas que pertenecen al orden de las convicciones morales; 0 más bien, a las que nos hacen reflexionar sobre la poca validez de las apariencias y sobre cómo, en el ámbito social, los hechos pueden ser y son interpretados de muchas maneras distintas. En Nostromo encontramos lo que podríamos llamar un escepticismo estructural, en ella aparece un narrador cuya experiencia es distinta de la del propio novelista y establece, por tanto, toda una serie de actitudes diferentes que niegan la simple certeza del lector. El narrador, en una creación artística del calibre de Nostromo, puede, gracias al dominio de la técnica que muestra su autor, colocarse en diferentes puntos temporales, a veces en puntos que están en el futuro de los acontecimientos que se están narrando en ese momento y desde los cuales las consecuencias de los hechos se han vuelto evidentes. El narrador, situado en esos puntos puede mirar al pasado o volver sobre otros hechos no explicados o no conocidos por el lector hasta ese momento. Este juego constante hace que la simple fe del lector en una cronología lineal se vea sacudida, y permite que novelas como Nostromo puedan mirar hacia el futuro con una fuerza poética que a veces es sorprendente por su valor predictivo.

El narrador no sólo se mueve en el tiempo, sino que puede colocarse o focalizarse en distintas conciencias y, dentro de ellas, en diversos momentos de la línea temporal. A veces, se trata de Decoud, y a veces de Mitchel, de Emilia Gould, de Monygham o del propio Nostromo. La siguiente afirmación, por ejemplo, es de Charles Gould y ocurre en la primera parte de la novela:

Lo que se necesita aquí son leyes, buena fe, orden, seguridad. Cualquiera puede declamar acerca de esas cosas, pero yo pongo mi fe en los intereses materiales. Solo hay que dejar que los intereses materiales se impongan firmemente una vez, y ellos mismos impondrán las condiciones en las que ellos solos puedan seguir existiendo. Así es como se justifica el hacer dinero aquí a la vista de la ilegalidad y el desorden. Se justifica porque la seguridad que eso demanda debe compartirse con un pueblo oprimido. Una justicia mejor vendrá después. Ese es su rayo de esperanza. ${ }^{2}$

${ }^{2}$ Ésta y las siguientes citas de Nostromo están tomadas de la edición de Penguin Books de 1971. Las traducciones son mías.

"What is wanted here is law, good faith, order, security. Anyone can declaim about these things, but I pin my faith to material interests. Only let the material interests once 
El escepticismo estructural al que aludía se hace evidente si se compara esta cita con la siguiente, en la cual habla el doctor Monygham casi al final de la novela, cuando se ha reestablecido la paz social y la prosperidad económica, y un gobierno ilustrado y liberal está en funciones:

No, [...] no hay paz ni descanso en el desarrollo de los intereses materiales. Ellos tienen su ley y su justicia. Pero está basada en la rapidez y es inhumana; no tiene rectitud, no tiene la continuidad y la fuerza que pueden hallarse sólo en un principio moral. Señora Gould, se acerca la hora en que todo lo que representa la concesión de la mina Gould pesará sobre el pueblo tanto como la barbarie, la crueldad y el desgobierno de hace algunos años. ${ }^{3}$

Es obvio que la existencia de puntos de vista tan diferentes dentro de una misma novela obliga al lector a juzgar por sí mismo y a cooperar con el autor de una manera que no hace al leer un texto de historia. En la novela, el lector no puede escoger un solo punto de vista; la estructura misma de la obra, su forma arquetípica, hacen que sea imposible quedarse siempre en un solo lado. El lector tiene que reestablecer el equilibrio simpatizando, a veces, con un personaje o punto de vista, $y$, a veces, con otro.

La cualidad profética de la novela a la que me referí arriba se muestra claramente en los pasajes citados, en los que se discuten algunos problemas a los que en la actualidad se enfrentan muchos países latinoamericanos que aún no superan ciertas etapas de desarrollo económico y social. A este respecto consideremos el siguiente pasaje en que la novela invade los terrenos de la historia contemporánea y se vuelve profecía. Habla Holroyd, el capitalista estadounidense que financia, en parte, la explotación de la mina de San Tomé:

Por supuesto que vendremos algún día. Estamos destinados a hacerlo. Pero no hay prisa. El tiempo mismo tiene que seguir el paso del

get a firm footing, and they are bound to impose the conditions on which alone they can continue to exist. That's how your money-making is justified here in the face of lawlessness and disorder. It is justified because the security which it demands must be shared with an oppressed people. A better justice will come afterwards. That's your ray of hope" (p. 81)

3 "No! [...] There is no peace and no rest in the development of material interests. They have their law, and their justice. But it is founded on expediency, and is inhuman; it is without rectitude, without the continuity and the force that can be found only in a moral pinciple. Mrs. Gould, the time approaches when all that the Gould Concession stands for shall weigh as heavily upon the people as the barbarism, cruelty, and misrule of a few years back" (p. 419). 
país más grande del universo de Dios. Daremos la palabra para todo: industria, comercio, leyes, periodismo, arte, política y religión. Desde el Cabo de Hornos hasta el estrecho de Smith y también más allá si en el Polo Norte aparece algo digno de apropiarse de él. Y entonces tendremos tiempo de apoderarnos de las islas y continentes de la tierra. Dominaremos los negocios del mundo, aunque al mundo no le guste. El mundo no puede oponerse. ${ }^{4}$

Si queremos afinar la distinción entre novela e historia, comparemos este pasaje con lo que sucede el día de hoy en muchos lugares de la tierra. Esta comparación permitirá completar el esbozo de definición de novela presentado anteriormente con algunas ideas tomadas de la obra citada de White. Se puede concluir, entonces, que la novela es una estructura verbal escrita en prosa predominantemente narrativa. Este discurso utiliza tanto su forma arquetípica como la prosa para representar estructuras y procesos que pudieron o no haber sucedido, pero, en cualquier caso, hace explícito su carácter ficticio. Se puede añadir, además, que su contenido parece ser aplicable a la realidad aunque hayan pasado muchos años desde que fue escrita.

4 "Of course, some day we shall step in. We are bound to. But there's no hurry. Time itself has go to wait on the greatest country in the whole of God's Universe. We shall be giving the word for everything: industry, trade, law, journalism, art, politics, and religion, from Cape Horn clear over to Smith's Sound, and beyond, too, if anything worth taking hold of turns up at the North Pole. And then we shall have the leisure to take in hand the outlying islands and continents of the earth. We shall run the world's business whether the world likes it or not. The world can't help it [...]" (p. 75). 